\title{
THE INVESTIGATION OF GRAIN GROWTH MECHANISMS IN SILICON STEELS
}

\author{
Ivan PETRYSHYNETS, František KOVÁČ, Martin SOPKO \\ Institute of Materials Research Slovak Academy of Sciences, Department of microstructural engineering of steels, Watsonova 47, \\ 04001 Košice, Slovak Republic, +421 55792 2448, e-mail: ipetryshynets@imr.saska.sk
}

\begin{abstract}
Different mechanisms of grain growth processes in grain-oriented (GO) steels are discussed. It has been shown that, application of particular thermomechanical treatment conditions leads to an appropriate microstructure and texture state in the investigated electrical steel. Short time annealing of the GO steel taken after final cold rolling reduction, at appropriate temperature leads to abnormal grain growth in the investigated steel. In this case, the Goss texture $(\{110\}<001>)$ is the major texture component in the treated samples. Combination of temper rolling with appropriative annealing conditions leads to columnar grain growth development in the investigated GO steel.
\end{abstract}

Keywords: Abnormal grain growth, columnar grains, Goss texture component, microstructure, coercivity.

\section{INTRODUCTION}

A wide range of technologically important properties of steels are controlled by the microstructure [1]. Due to crystalline anisotropy preferred orientation in steels also important characteristic parameter from final properties point of view. The microstructure as well as texture parameters are depended on whole processing rote of steels production. Although the technology of microstructure control of the steel is quite developed however the texture control still remains an exciting challenge for materials science. The most successful texture control has been achieved in production of GO steels [2]. These kinds of steels are mainly used in transformers and large power generators as core materials. For high magnetic induction and low core losses during premagnetization, these types of steels should have a sharp $\{110\}<001>$ texture in the final state. This texture develops during secondary recrystallization or in other words, abnormal grain growth of $\{110\}<001>$ oriented grains [2]. The exact mechanism of the Goss grain growth is not completely understood, so far.

The abnormal grain growth (AGG) in GO steels can be achieved under very precise and complicate industrial processes by energy and time consuming technology [3]. The most power-consuming treatment step is the box annealing process which comprises quite slow heating up to purification temperature $1200^{\circ} \mathrm{C}$ (heating rate $\sim 25$ $30^{\circ} \mathrm{C}$ /hour) and annealing at this temperature for about 20 hours [3]. This energy-consuming production technology leads the researchers to searching of possible reduction of manufacturing cost [4]. Evidently in the last years, this aspect has become the mainspring for most of the industrial research and development activities.

The present work was made to unveil electrotechnical steels treatment potentials which could be applicable in industrial production. The two different types of grain growth are considered. The first one is abnormal grain growth, which have been achieved in GO steel taken from industrial line after final cold rolling reduction. The second one is columnar grain growth developed in GO steels taken from industrial line after first cold rolling and decarburization annealing. Both types of achieved microstructure are favourable for particular grade of electrotechnical steels used under adequate service conditions.

\section{EXPERIMENTAL PROCEDURE}

Grain-oriented electrical steel taken from industrial line after different steps of cold rolling reductions was used as experimental material. The samples $\mathrm{F}$ and $\mathrm{S}$ were taken after first and second steps of industrial cold rolling reduction, respectively. The sample $\mathrm{F}$ was after industrial pickling of $2.5 \mathrm{~mm}$ thick hot rolled strip with subsequent first cold rolling to the thickness of $0.65 \mathrm{~mm}$ and industrial decarburization annealing. The sample $\mathrm{S}$ was taken after subsequent steps of industrial production line of the same steel as sample F, i.e. after second cold rolling to the thickness of $0.30 \mathrm{~mm}$ which was made in three rolling paths. Both samples $\mathrm{F}$ and $\mathrm{S}$ were characterized by the following chemical composition: $\mathrm{C}=0.006, \mathrm{Mn}=$ $0.21, \mathrm{Si}=3.15, \mathrm{P}=0.007, \mathrm{~S}=0.009, \mathrm{Cr}=0.003, \mathrm{Cu}=$ $0.44, \mathrm{Al}=0.013, \mathrm{~N}=0.011$ wt. $\%$.

Sample $\mathrm{F}$ was divided into three groups and each of them was laboratory temper rolled with $5 \%, 9 \%$, and $14 \%$ of reduction in thickness. Hence three groups of specimens were received F1, F2 and F3 with applied 5\%, $9 \%$, and $14 \%$ temper rolling reduction, respectively. Prepared in this way samples were subjected to laboratory heat treatment in dry hydrogen atmosphere at different time-temperature expositions. The steel $\mathrm{S}$ taken from industrial line was directly annealed under particular laboratory conditions.

The laboratory heat treatment was realized by furnace "Nabertherm" with an electronic control system C19/S19. Holding time at the temperature was $5 \mathrm{~min}$. The investigated samples were laboratory annealed in a wide range of temperature which was changed from $850^{\circ} \mathrm{C}$ up to $1100^{\circ} \mathrm{C}$.

The microstructure of the investigated specimens was examined in the longitudinal cross-section and in the normal direction plane using light microscopy. Crystallographic texture of the treated specimens was carried out by EBSD method. The JEOL JSM 7000F FEG SEM was employed to perform the texture analysis. The EBSD data were collected from the longitudinal crosssection of the treated specimens. 
The main microstructure and texture changes in the investigated samples also were followed by coercive force measurements. Coercive forces of the investigated steels were measured by standard coercive-meter KPS-1c. Samples for these measurements were in size $1 \mathrm{~cm}$ by 3 $\mathrm{cm}$ (longest side was parallel to the RD of the sample).

\section{RESULTS AND DISCUSSION}

As was already mentioned, the GO steel samples were cut into 1 by $3 \mathrm{~cm}$ rectangles; the longest rectangle side was parallel to the RD. Such samples from S series were annealed at different temperatures for $5 \mathrm{~min}$. It was made to find out a temperature at which the AGG will start, possibly to proceed or/and completely develop in the investigated samples. It was found that fully recrystallized microstructure of the $\mathrm{S}$ specimens can be achieved after annealing at $850^{\circ} \mathrm{C}$ for $5 \mathrm{~min}$. This microstructure state is presented in Fig. 1a. Thermal exposition of sample $S$ at temperature $950^{\circ} \mathrm{C}$ leads to start of abnormal grain growth, this microstructure state is presented in Fig. 1b. Complete abnormal grain growth progress was received after annealing of the investigated GO steel at $1000^{\circ} \mathrm{C}$ for $5 \mathrm{~min}$, see Fig. 1c. Increasing of the annealing temperature to $1050^{\circ} \mathrm{C}$ leads to broken of selectivity conditions for AGG, hence the abnormal grain growth is not so pronounced in this case, see Fig. 1d. Hence, the abnormal grain growth in grain oriented steels is possible at short time annealing conditions (under dynamical heat treatment conditions) and at appropriate unique temperature.

The significantly distinguish type of microstructure have been achieved in laboratory temper rolled samples of F series. The samples were directly annealed at different temperature for $5 \mathrm{~min}$ in dry hydrogen atmosphere under laboratory conditions. The columnar grained microstructure developed in specimen F1 annealed at $950^{\circ} \mathrm{C}$, see Fig. 2a. Annealing of these samples at higher temperature $\left(1000^{\circ} \mathrm{C}\right)$, leads to equiaxial grain growth development. The equiaxial grain microstructure has smaller mean grain size than that in the columnar one, compare Fig. 2a and 2b. The main benefits of the columnar microstructure in comparison with the equiaxial one, was discussed by authors of the Ref. [5]. Here was concluded that, the columnar microstructure is much favourable than the equiaxial one from magnetic point of view.

The microstructure of samples F2 and F3 annealed at $950^{\circ} \mathrm{C}$ for $5 \mathrm{~min}$ is presented in Fig. 3a and $3 \mathrm{~b}$ respectively. It is clearly visible that increasing of reduction intensity leads to decreasing of mean grain size of the annealed samples, compare the Fig. 3a and 3b. Moreover, the further increasing of the annealing temperature has little effect on the mean grain size of the investigated samples of $F$ series. This could be because of the presence of second phase particles which have the retarding effect on grain boundary motion. Also it is necessary to note that the temper rolled samples of $\mathrm{F}$ series were annealed at wide range of temperatures. However, the abnormal grain growth was not observed in this series of annealed samples. This results one lead to conclusion, that the applied temper rolling reduction in
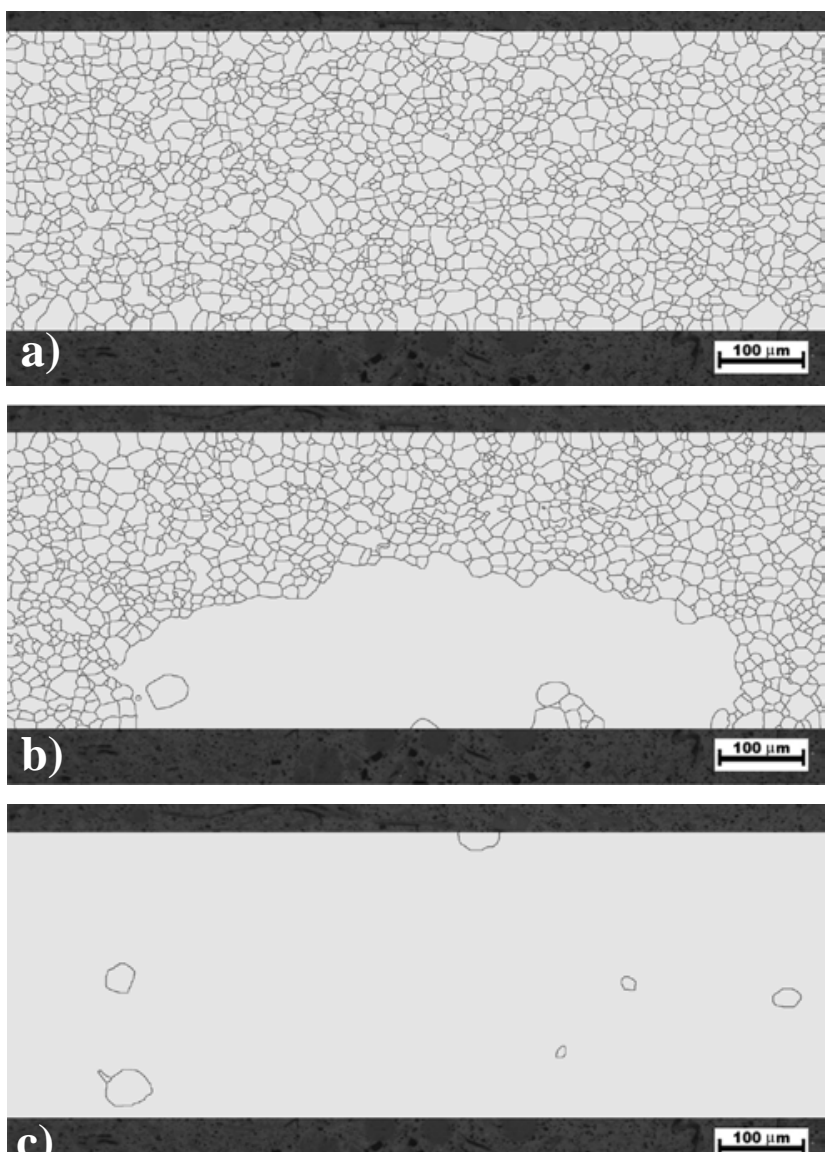

c)

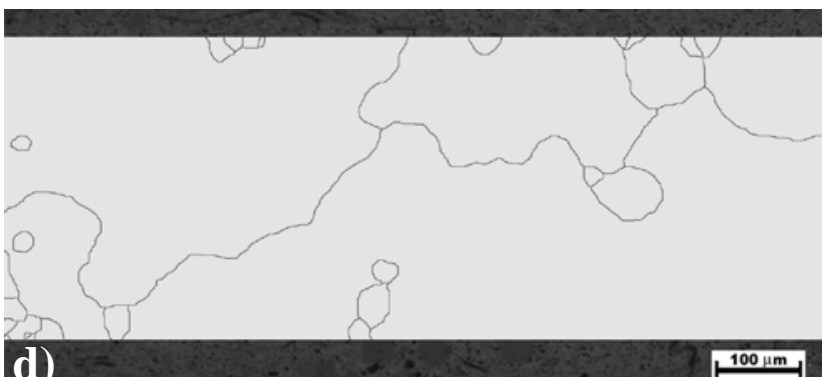

Fig. 1 Microstructure of S samples annealed at a) $850^{\circ} \mathrm{C}$; b) $950^{\circ} \mathrm{C}$; c) $1000^{\circ} \mathrm{C}$ and c) $1050^{\circ} \mathrm{C}$ for $5 \mathrm{~min}$ in dry hydrogen atmosphere (d.p. $\left.=-30^{\circ} \mathrm{C}\right)$

range of $5 \%-14 \%$, which can be considered as second one, is not sufficient for abnormal grain growth development in the investigated GO steels.

The texture states of the microstructure shown in Figs. 1c and 2a are presented in Figs. 4a and 4b respectively. It is clear that the abnormal grain growth in sample $S$ leads to development of Goss texture which is undoubtedly visible from the presented ODF section, see Fig. 4a. The mean deviation of the obtained Goss grains from the ideal orientation is less than $8^{\circ}$, which is typical for conventional GO steels [6]. The texture of the sample with columnar microstructure has a strong cubic component $(001)<110>$ the second quite intensive texture component in the mentioned microstructure is $(113)<223>$. Very weak component of $(114)<223>$ texture is also observed in this texture state, see Fig. 4b. However, it could be confirmed that the major component in the obtained columnar microstructure is the cubic or in the other word "rotating cube" texture component. 

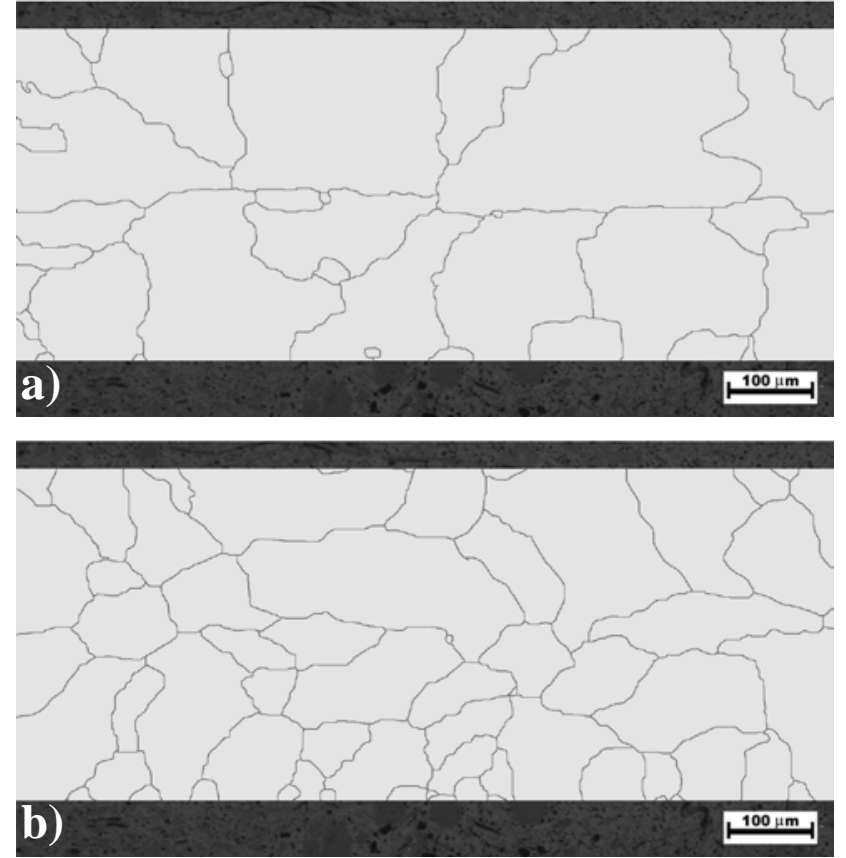

Fig. 2 Microstructure of sample F1 cold rolled under laboratory condition with $\varepsilon \sim 5 \%$ and subsequently annealed at a) $950^{\circ} \mathrm{C}$ and b) $1000^{\circ} \mathrm{C}$ for $5 \mathrm{~min}$ in dry hydrogen atmosphere (d.p. $=-30^{\circ} \mathrm{C}$ )

Magnetic properties of the investigated GO steel are very sensitive to microstructure and texture state changes. In this work coercivity measurements were utilized to reflect the main microstructure and texture changes as results of the applied laboratory treatments of the investigated samples. Fig. 5 presents changes in the coercivity $H_{C}$ as a function of annealing temperature for samples of $\mathrm{F}$ series, with particular temper rolling reduction, and for sample $\mathrm{S}$. A quite steep decrease in $H_{C}$ values observed in samples $\mathrm{F} 1$ series which was temper rolled with $\varepsilon \sim 5 \%$. The lowest value of the measured coercivity was observed for sample annealed at $950^{\circ} \mathrm{C}$ for 5 min. This corresponds to the columnar microstructure development with pronounced cubic texture component.
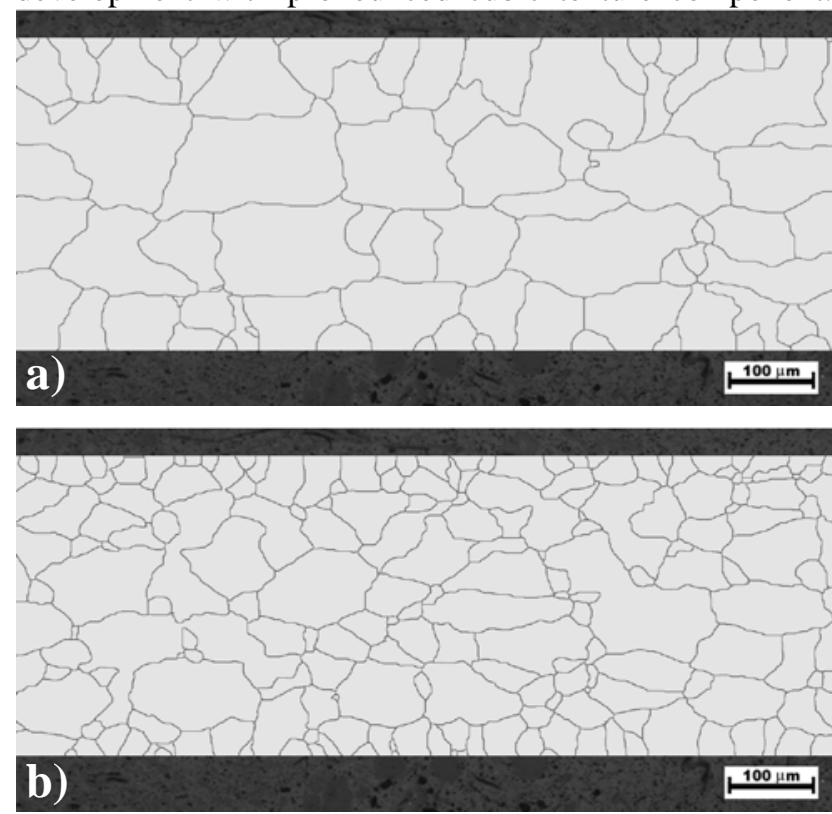

Fig. 3 Microstructure of samples F2 and F3 cold rolled under laboratory condition with a) $\varepsilon \sim 9 \%$ b) $\varepsilon \sim 14 \%$ and subsequently annealed at $950^{\circ} \mathrm{C}$ for $5 \mathrm{~min}$ in dry hydrogen atmosphere (d.p. $=-30^{\circ} \mathrm{C}$ )
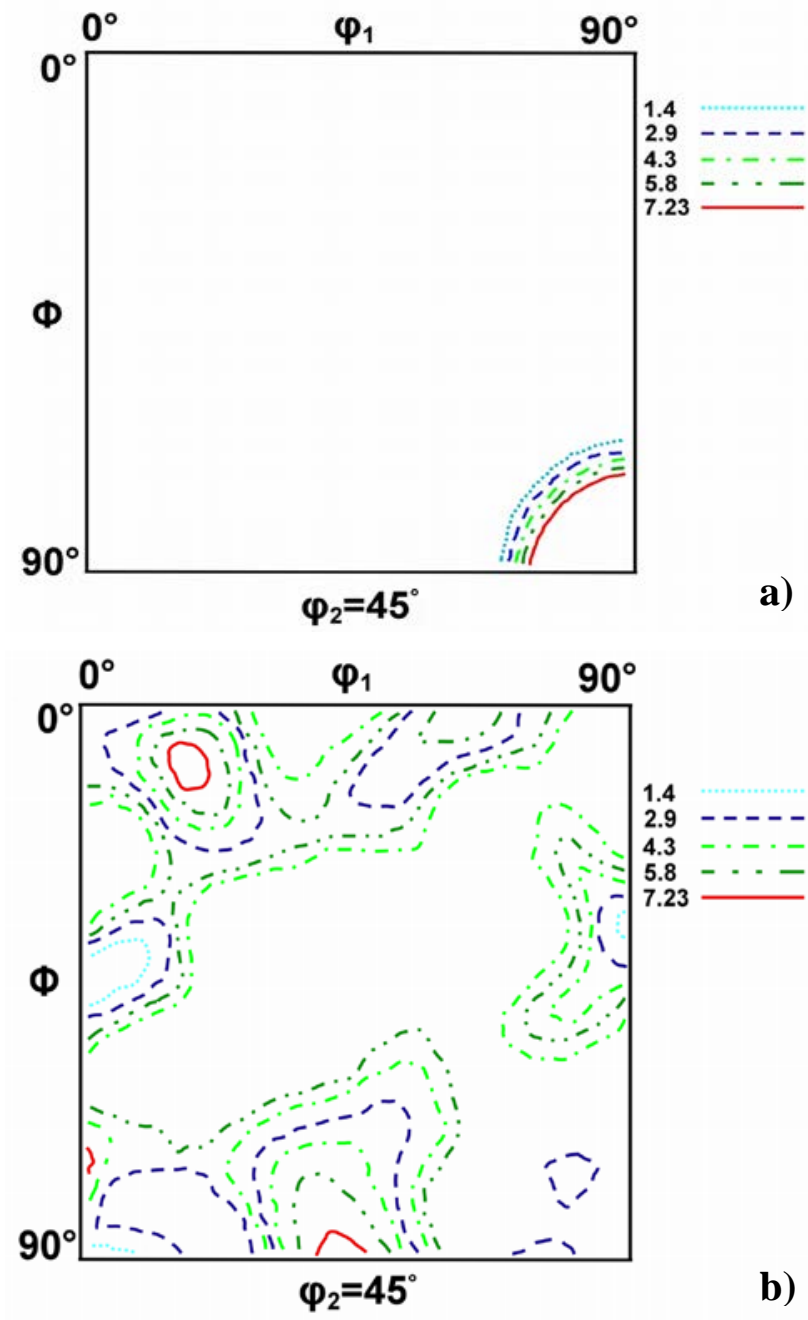

Fig. 4 ODFs of the samples a) with abnormal grains microstructure presented in Fig. 1c; and b) with columnar microstructure shown in Fig. 2a

Increasing of annealing temperature leads to increase of $H_{C}$ values, see Fig. 5 . This phenomenon could be assigned to the fact, that the equiaxial grained microstructure develops during the annealing at these temperatures, see Fig. 2b. The equiaxial microstructure has smaller mean grain size and the cubic texture components are in a minority in such microstructure state. Coercive forces measured on other temper rolled samples, with higher reduction, showed much higher values of the magnitude. It is clearly visible that increasing of temper rolling reduction leads to increase of coercive forces values within all applied annealing temperature region. The increase of coercive forces is explained by mean grain size decreasing in equiaxial microstructure for samples with higher temper rolling reduction, for instance see Figs. 2 and 3. Hence, the coercive force measurements also confirms, that the conditions for columnar grain growth are temper rolling $(\varepsilon \sim 5 \%)$ with subsequent annealing that appropriative for this type of grain growth (i.e. $\sim 950^{\circ} \mathrm{C}$ ).

The completely different behaviour of coercivity dependence on annealing temperature was observed for samples S. The $H_{C}$ values for annealed samples of S series were considerably higher than that for samples of $\mathrm{F}$ one. However, this phenomenon was observed for samples $\mathrm{S}$ annealed only at temperature range from $850^{\circ} \mathrm{C}$ to $900^{\circ} \mathrm{C}$. Annealing of S samples at temperature $950^{\circ} \mathrm{C}$ and higher 


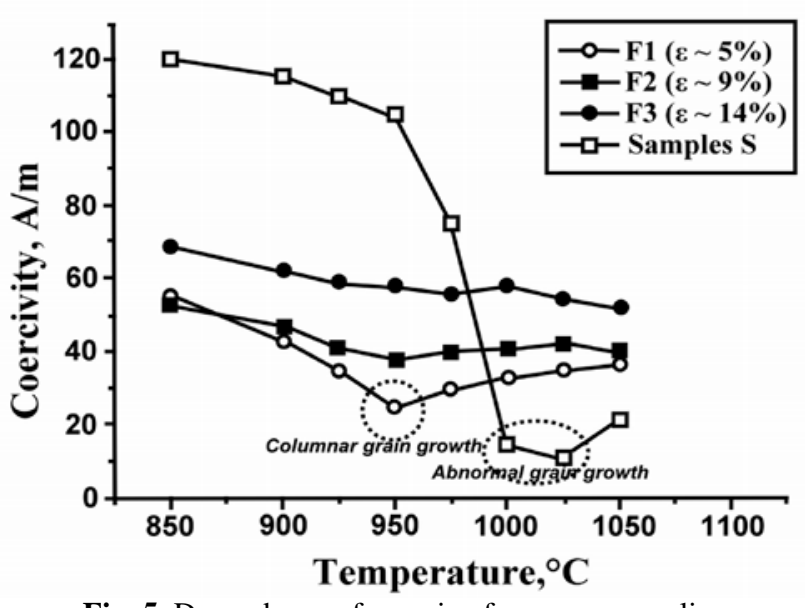

Fig. 5 Dependence of coercive forces on annealing temperatures in samples of S series; temperatures and applied cold rolling reduction in temper rolled $\mathrm{F}$ samples

leads to quite steep decreasing of the coercivity values; see Fig.5 (chart for samples S). The mentioned decrease and short plateaus behaviour of $H_{C}$ curve can be followed with further increasing of annealing temperature. The rapid slant of $H_{C}$ curve can be explained by beginning of AGG i.e. bimodal microstructure development, as shown on Fig. 1b. The short plateaus behaviour of the coercive force curve reflects the complete abnormal grain growth development within the appropriative temperature region.

Columnar microstructure development as favourite microstructure from the magnetic properties point of view for Non-oriented electrical steels was proposed in Ref. [5]. In this case the authors emphasized vital role of carbon content in the steels, and assigned the columnar grains formation mechanism to diffusion controlled grain growth by carbon diffusion [7]. However, the columnar microstructure derived from low temper rolling reduction has completely different mechanism as that described in Refs. [5,7]. The columnar grain growth development in the temper rolled GO steel presented in this work is assigned to so called strain induced boundary motion (SIBM) mechanism. Hence, applied low temper rolling in combination with appropriative heat treatment leads to grow of surface grains into the mid-thickness region.

As it was mentioned, the abnormal grain growth phenomenon represents a great interest and challenge for scientist working in materials research. This is because the knowledge of exact mechanism of this kind of grain growth is still rudimentary. As it was shown in the present work the AGG can be obtained under short time annealing (5 min) at considerably high temperature $\left(\sim 1000^{\circ} \mathrm{C}\right)$. The observed in this work phenomenon of AGG under dynamical heat treatment conditions arouses interest and additional questions about the exact mechanism of this kind of grain growth.

\section{CONCLUSIONS}

The present work presents the main results of modelling heat treatment with combination of temper rolling which were realized on GO steels strips taken after different steps of industrial production. The mentioned experimental procedures have been lead to drastic reduction of time necessary for abnormal grain growth development in GO steels. However, it is necessary to note that, the second particles are still presented in the investigated steel after the short time annealing. Hence further purification annealing is necessary to carry out in order to dissolute and remove the elements creating these second phase particles. Moreover, the columnar grain microstructure was achieved in GO steel by strain induced grain boundary motion mechanism. This columnar grain growth presents a great interest for non-oriented steels production from good magnetic properties point of view. The columnar grain growth achieved in GO steels despite the presence of second phase particles confirms the fact of possibilities of achievement the same kind of grain growth in FeSi non-oriented steels.

\section{ACKNOWLEDGMENT}

This work was carried out within the framework of the project "Research Centrum for Combinated and Renewable Resources of Energy”, ITMS 26220220064 financed through the European Regional Development Fund.

\section{REFERENCES}

[1] HUMPREYS, F. J. - HATHERLY, M.: Recrystallization and related annealing phenomena, Oxford, Pergamon, p. 497, 1996.

[2] GOSS, N. P.: Electrecal sheet and method and apparatus for its manufacture and test, U.S. Patent no. 1,965,559, 1934.

[3] CHANG, S. K. - HONG, B. D.: Secondary Recrystallization Behavior in 3\% Si Grain Oriented Steels, ISIJ International, vol. 44, no. 6, pp. 10861092, 2004.

[4] GÜNTHER, K. - ABBRUZZESE, G. FORTUNATI, S. - LIGI, G.: Recent technology development in the production of grain oriented electrical steel, SMM 16, Düsseldorf, pp.41-50, 2003.

[5] KOVÁČ, F. - DŽUBINCKÝ, M. - SIDOR, Y.: Columnar grain growth in non oriented electrical steels J. Magn. Magn. Mater, 269, pp.333-340, 2004.

[6] MATSUO, M.: Texture Control in the Production of Grain Oriented Silicon Steels, ISIJ International, vol. 29, no. 10, pp. 809-827, 1989.

[7] KOVÁČ, F. - NIŽNÍK, Š.: Columnar grain growth in nonoriented Si-steels (in Slovak), Kovové Materiály, vol. 34, no. 2, pp. 105 - 112, 1996.

Received November 9, 2012, accepted February 12, 2013

\section{BIOGRAPHY}

I. Petryshynets was born on 05.04.1984. In 2001 he graduated (MSc) with distinction at the Department of Theoretical Physics of the Faculty of Physics at Uzhgorod National University. He defended his PhD in the field of Materials Science and Engineering in 2006; his thesis title was "Strain induced grain boundary migration in electrotechnical steels“. Since 2006 he is working as a scientific researcher at the Institute of Materials Research, Slovak Academy of Sciences, Department of Microstructural Engineering of Steels. His scientific research is focusing on the grain-oriented and nonoriented electrical steels investigation and development of new steels types/qualities. 